\title{
Knowledge of Dental Notation System in a Dental Teaching Hospital of Karachi
}

\author{
Umaima Khan ${ }^{1}$ \\ BDS \\ Beenish Fatima Alam ${ }^{2}$ \\ BDS, MSc, MFDS RCS(Ed) \\ Talha Nayab ${ }^{3}$ \\ BDS, MSc \\ Ahsan Inayat ${ }^{4}$ \\ BDS \\ Muhammad Faisal Fahim ${ }^{5}$ \\ MSc
}

\author{
Ayesha Wahab Khan
}

OBJECTIVE: To identify the various types of dental notation system preferred by students working within the dental hospital and to evaluate the tooth notation methods favored by the different clinical departments in a dental teaching hospital of Karachi. METHODOLOGY: This Cross sectional study was conducted within the dental hospital of Bahria University Medical and Dental College. The survey employed for this study was modified from the study lead by Al-Johany SS. All the qualitative variables are presented as frequency and percentages. Chi-square or Fischer exact test was applied to see the significance $\mathrm{P}$-value $<0.05$ considered to be statistically significant.

RESULTS: A total of 153 students participated in the study. FDI was commonly understandable tooth Numbering system by $66 \%(n=48)$ of the final year students while $49 \%(n=39)$ of the house officers preferred Universal system. For coding primary teeth palmer system was identified, while for permanent dentition FDI was preferred.

CONCLUSION: This study clearly highlights that different method for tooth numbering will be used continually by the dental professionals. Realistic approach is to make sure that dental professionals have sufficient knowledge regarding the most commonly used numbering systems and are responsive towards the pitfalls in each system.

KEYWORDS: Notation, Tooth numbering system (TNS), FDI, Palmer, Universal system

HOW TO CITE: Khan U, Alma BF, Nayab T, Inayat A, Fahim MF, Khan AW. Knowledge of dental notation system in a dental teaching hospital of Karachi. J Pak Dent Assoc 2020;29(3):151-155.

DOI: https://doi.org/10.25301/JPDA.293.151

Received: 15 January 2020, Accepted: 08 May 2020

\section{INTRODUCTION}

$\mathrm{T}$ ooth numbering system serves as a means for identification, recording and management of dental patients. ${ }^{1}$ It specifically identifies the teeth by numbers or alphabets which are used for charting and communiqué purposes. ${ }^{2}$ Incisors, canine, premolars and molars are the dental expressions used worldwide for all human teeth. ${ }^{3}$

1. Lecturer, Department of Oral Biology, Bahria University Medical and Dental College.

2. Assistant Professor, Department of Oral Biology, Bahria University Medical and Dental College.

3. Assistant Professor, Dental Materials, Jinnah Sindh Medical University

4. MDS Resident, Division of Prosthodontics, Dow University Health Sciences.

5. Researcher \& Consultant Statistician, Department of Bahria University College of Physical Therapy (BUCPT)

6. BDS student, Department of Oral Biology, Bahria University Medical and Dental College.

Corresponding author: "Dr. Beenish Fatima Alam” < nish_alam@yahoo.com >
Miscommunication during referral cases among the dentist in specifying the tooth can cause serious misinterpretation. ${ }^{4}$ To avoid these mishaps it is necessary for the dentist to use tooth numbering system that allows accurate teeth identification. $^{5}$

Most commonly opted tooth numbering systems are, Universal numbering system, Federation Dentaire Internationale (FDI) and Palmer notation, which are frequently used by the dental surgeons while the dental hygienists can freely select any system for detection and conveying of dental details to others. ${ }^{6}$

FDI is a two-digit numbering tool which is widely employed in various regions. ${ }^{7,8,9}$ In this system, among the two digits the first number represents the quadrant (1-4) starting from upper right, upper left, lower left, and lower right and the second number represents the tooth (1-8). ${ }^{7}$

The Universal Numbering System for permanent dentition 
starts from the third molar of upper right quadrant which is identified as \# 1 and the further counting of teeth continues clockwise from the maxillary right quadrant to maxillary left quadrant and then from the mandibular left third molar to mandibular right third molar which is nominated as \#32. ${ }^{7}$ Zsigmondy or Palmer notation system, another tool for denoting permanent dentition, begins from central incisor and continues to the third molar of each quadrant. It is counted from mesial end to distal end as 1 to 8 in each quadrant for example central is designated as \#1 and the third molar designated as \#. ${ }^{8}$ To identify the quadrant position, a gridiron sign located above or below the number. ${ }^{7,10}$ All the existing systems of tooth notation have its own advantages and disadvantages6.FDI system is safe and easy to utilize because of its accurateness and reliability to current technology, this system is considered as one of the best tooth numbering system.11 while the Zsigmondy/Palmer system is difficult to pronounce and interpret into computer input $^{7,11,12,13}$ Similarly, the universal tooth numbering is difficult to memorize and communicate and there is no midline differentiation. ${ }^{11,12,13,14}$

Different notations are preferred in the different parts of the world, Federation Dentaire Internationale (FDI) system most commonly implemented within European region. Whereas Universal numbering system is more common in the Canada and US. ${ }^{3,15}$ Additionally Palmer notation is quite popular in Great Britain and Asian countries., ${ }^{3,16}$ Previously conducted researches in Pakistan have focused on making comparison between Universal or FDI with the newer introduced (Molar, Incisor, Canine, Premolar and A-akram (the dentist) MICAP tooth numbering system. None of the studies conducted have focused on analyzing the most commonly used tooth numbering system within various dental colleges of Pakistan. The main purpose of the current research was to detect the most preferred tooth numbering system by final year students and dentists to identify a particular tooth while working in the dental departments at Bahria University Medical and Dental College as well as the most preferred tooth notation system employed by different clinical departments.

\section{METHODOLOGY}

This is cross sectional study was conducted over 153 students of 4th year B.D.S and the House officers designated in dental OPD of Bahria University Medical and Dental College, over a period of 6 months from June 2019 to November 2019 . The ethical approval of the study was obtained by the ethical review committee of Bahria University Medical and Dental College (ERC 50/2019). Students willing to participate were included while the participants unwilling and students of 1st and 2nd year BDS were excluded as they did not visit the Dental OPD, while 3rd year visited the OPD partly and did not visit all the clinical departments hence were excluded as well.

A written consent was obtained from all the students before distribution of questionnaires. The survey required 5 mins for completion. The questionnaire utilized for this study was modified from the study conducted by Al-Johany SS a previously reported study but the setting was performed according to our clinical setting. ${ }^{17}$ The initial part of the survey comprised of the gender and year at the dental college. The subsequent part focused on the questions related to most understandable Tooth numbering system, Tooth notation preferred for primary, permanent dentition and for supernumerary teeth, dental coding system used by the clinical department, problems encountered by using incorrect tooth notation.

\section{STATISTICAL ANALYSIS}

Sample size was calculated using OpenEpiTM3. Statistical conditions used were $95 \%$ confidence interval with 5\% margin of error. The required sample size was found to be $153 .{ }^{17}$ The collected data was analyzed using SPSS version 23.0 to enter data. All the qualitative variables are presented as frequency and percentages. Chi-square or Fischer exact test was applied to see the significance $\mathrm{P}$-value $<0.05$ considered to be statistically significant.

\section{RESULTS}

A total of 153 students participated in the study. This included $33 \%(\mathrm{n}=51)$ male participants while the female participants were $67 \%(n=102)$. Final year B.D.S students were $48 \%$ $(n=73)$ and $52 \%(n=80)$ House officers. FDI was most commonly understandable TNS by $66 \%(n=48)$ Final year students and 49\% ( $n=39)$ House officers, while the Universal system was chosen by $28.8 \%(n=21)$ Final year students and $26.3 \%(n=21)$ House officers. Coding system utilized for primary teeth was palmer system by $49 \%(n=39)$ House officers and 38\% (n=28) Final year BDS students. For denoting permanent teeth FDI was favoured by $78 \%$ $(n=62)$ House officers followed by $60 \%(n=44)$ Final year students. Tooth numbering system employed for identification of supernumerary teeth was universal system by $45 \%(n=33)$ Final year students, while 38\% ( $n=30)$ House officers did not know.

When enquired regarding the most frequently used TNS within the department of Operative Dentistry, $85 \%(n=62)$ Final year students and 66\% (n=53) House officers recommended using FDI system, followed by Palmer system. 
Khan U/ Alma BF/ Nayab T/

Inayat A/ Fahim MF/ Khan AW

Table 1: Analysis of responses received regarding the Tooth notation system

\begin{tabular}{|c|c|c|c|c|c|}
\hline & & \multicolumn{2}{|c|}{ Class } & \multirow[b]{2}{*}{ Total } & \multirow[b]{2}{*}{ P-value } \\
\hline & & $\begin{array}{c}\text { 4th year } \\
(\mathrm{n}=73)\end{array}$ & $\begin{array}{c}\text { house officer } \\
(\mathrm{n}=80)\end{array}$ & & \\
\hline \multirow{6}{*}{$\begin{array}{l}\text { Tooth numbering most } \\
\text { easiest to learn/understand }\end{array}$} & FDI & 48 & 39 & 87 & \multirow{6}{*}{0.003} \\
\hline & & $65.8 \%$ & $48.8 \%$ & $56.9 \%$ & \\
\hline & Universal & 21 & 21 & 42 & \\
\hline & & $28.8 \%$ & $26.3 \%$ & $27.5 \%$ & \\
\hline & Palmer & 4 & 20 & 24 & \\
\hline & & $5.5 \%$ & $25.0 \%$ & $15.7 \%$ & \\
\hline \multirow{6}{*}{$\begin{array}{l}\text { Tooth numbering system } \\
\text { used for primary dentition }\end{array}$} & FDI & 18 & 28 & 46 & \multirow{6}{*}{0.014} \\
\hline & & $24.7 \%$ & $35.0 \%$ & $30.1 \%$ & \\
\hline & Universal & 27 & 13 & 40 & \\
\hline & & $37.0 \%$ & $16.3 \%$ & $26.1 \%$ & \\
\hline & Palmer & 28 & 39 & 67 & \\
\hline & & $38.4 \%$ & $48.8 \%$ & $43.8 \%$ & \\
\hline \multirow{6}{*}{$\begin{array}{l}\text { Tooth numbering system } \\
\text { used for Permanent teeth }\end{array}$} & FDI & 44 & 62 & 106 & \multirow{6}{*}{0.006} \\
\hline & & $60.3 \%$ & $77.5 \%$ & $69.3 \%$ & \\
\hline & Universal & 16 & 4 & 20 & \\
\hline & & $21.9 \%$ & $5.0 \%$ & $13.1 \%$ & \\
\hline & Palmer & 13 & 14 & 27 & \\
\hline & & $17.8 \%$ & $17.5 \%$ & $17.6 \%$ & \\
\hline \multirow{10}{*}{$\begin{array}{l}\text { Tooth numbering system } \\
\text { used for supernumerary } \\
\text { teeth }\end{array}$} & Universal & 33 & 3 & 36 & \multirow{10}{*}{0.000} \\
\hline & & $45.2 \%$ & $3.8 \%$ & $23.5 \%$ & \\
\hline & FDI & 11 & 17 & 28 & \\
\hline & & $15.1 \%$ & $21.3 \%$ & $18.3 \%$ & \\
\hline & Palmer & 17 & 15 & 32 & \\
\hline & & $23.3 \%$ & $18.8 \%$ & $20.9 \%$ & \\
\hline & Haderup & 0 & 15 & 15 & \\
\hline & & $0.0 \%$ & $18.8 \%$ & $9.8 \%$ & \\
\hline & Don't know & 12 & 30 & 42 & \\
\hline & & $16.4 \%$ & $37.5 \%$ & $27.5 \%$ & \\
\hline
\end{tabular}

Table 2: Association between most preferred TNS used in different dental departments

\begin{tabular}{|c|c|c|c|c|c|}
\hline & & \multicolumn{2}{|c|}{ Class } & \multirow[b]{2}{*}{ Total } & \multirow[b]{2}{*}{ P-value } \\
\hline & & $\begin{array}{c}\text { 4th year } \\
(\mathrm{n}=73)\end{array}$ & $\begin{array}{c}\text { House officer } \\
(\mathrm{n}=80)\end{array}$ & & \\
\hline \multirow{6}{*}{$\begin{array}{l}\text { TNS preferred in } \\
\text { Operative }\end{array}$} & FDI & 62 & 53 & 115 & \multirow{6}{*}{0.018} \\
\hline & & $84.9 \%$ & $66.3 \%$ & $75.2 \%$ & \\
\hline & UNIVERSAL & 4 & 6 & 10 & \\
\hline & & $5.5 \%$ & $7.5 \%$ & $6.5 \%$ & \\
\hline & PALMER & 7 & 21 & 28 & \\
\hline & & $9.6 \%$ & $26.3 \%$ & $18.3 \%$ & \\
\hline \multirow{6}{*}{$\begin{array}{l}\text { TNS preferred in } \\
\text { orthodontics }\end{array}$} & FDI & 38 & 38 & 76 & \multirow{6}{*}{0.159} \\
\hline & & $52.1 \%$ & $47.5 \%$ & $49.7 \%$ & \\
\hline & UNIVERSAL & 19 & 14 & 33 & \\
\hline & & $26.0 \%$ & $17.5 \%$ & $21.6 \%$ & \\
\hline & PALMER & 16 & 28 & 44 & \\
\hline & & $21.9 \%$ & $35.0 \%$ & $28.8 \%$ & \\
\hline \multirow{6}{*}{$\begin{array}{l}\text { TNS used in Oral } \\
\text { Surgery }\end{array}$} & FDI & 18 & 18 & 36 & \multirow{6}{*}{0.409} \\
\hline & & $24.7 \%$ & $22.5 \%$ & $23.5 \%$ & \\
\hline & UNIVERSAL & 44 & 43 & 87 & \\
\hline & & $60.3 \%$ & $53.8 \%$ & $56.9 \%$ & \\
\hline & PALMER & 11 & 19 & 30 & \\
\hline & & $15.1 \%$ & $23.8 \%$ & $19.6 \%$ & \\
\hline
\end{tabular}

FDI was also utilized by the $52 \%(\mathrm{n}=38)$ Final year students and $47.5 \%(n=38)$ House officers within the Orthodontic department. While in the Oral surgery department Universal TNS was usually used.

Major consequence of not following the correct TNS was wrong tooth extraction by $48.4 \%$ participants followed
Knowledge of Dental Notation System in a Dental Teaching Hospital of Karachi

by difficulty in communication between the clinicians by $33.3 \%$ of the participants.

\section{DISCUSSION}

Adequate knowledge of tooth numbering system is essential in performing adequate clinical practice of dentistry at both undergraduate and post graduate level. It not only helps in making the correct diagnosis but also helps during treatment planning sessions and in case of referring patients to dental specialists.

This study revealed that FDI is the most easily understood tooth numbering system by the $57 \%$ of the participants. These results are in accord with the research conducted by Sharma and Wadhwa, who stated that $74 \%$ of the dental students favored using FDI, as compared to other notation systems. ${ }^{18}$ It can be attributed to the fact that it is quite easy to understand and communicate with other fellow clinicians. Palmer notation system was commonly used by the $44 \%$ of the participants for denoting primary dentition. However these results contrasts with the study conducted by Al-Johany SS, who stated that $68 \%$ of the respondents used FDI system to denote primary teeth, followed by palmer system. ${ }^{19}$ Palmer system being quite easy to understand and record manually and tends to denotes primary teeth with upper case letters (A-E) makes it accessible to use in our setting.

For denoting permanent dentition FDI was chosen by $69 \%$ of final year students and house officers. These results are in agreement with the study carried out by different researchers who noted that FDI was primarily used notation system for communicating with their patients and colleagues, as this system is totally number based, unlike the other systems. ${ }^{19,20}$

Identifying supernumerary teeth helps in overcoming confusion and facilitates improved communication between the different dental professionals. In the current study, $45 \%$ of the Final year students identified Universal system to represent supernumerary teeth, while $38 \%$ of the house officers had no idea regarding the tooth numbering system for coding extra teeth. A study conducted by Toureno L et al, revealed that letter (for instance "A," or "S") can be added with the permanent tooth number to code the presence of extra teeth. ${ }^{21}$ Additionally other researchers identified Universal Supernumerary notation system that defines the teeth from \#51 to \#82 to supplement the original Universal System and hence overcomes any confusion within the system. $^{22}$

About $85 \%$ of the participants answered using FDI system to identify the teeth within the department of Operative dentistry. Interestingly a research conducted in UK revealed contrasting results that majority of the dental colleges used 
Palmer system for clinical diagnosis and treatment planning as it allows multiple teeth to be coded quickly. ${ }^{23}$

In the current study statistically insignificant results were noted for tooth notations system used within the Orthodontic and Oral surgery department.50\% of the respondents replied using FDI system for coding teeth, in Orthodontic department, additionally Universal system was used $57 \%$ of the participants within the department of Oral surgery . Study carried out by Pogrel identified that in U.S.A Palmers system is preferred by the orthodontist, while majority of the oral surgeons employed Universal system. ${ }^{24}$ Universal notation system follows a sequential pattern of identifying the teeth, while Palmer system produces 'graphical image of teeth'. However usage of two different notation systems amongst the dental specialists can cause alot of confusion while maintaining dental records or sending data for insurance purpose, as upper right 6 in Palmer is tooth number 3 in Universal tooth numbering system.

Several potential problems can arise in case of not following correct tooth notation especially during referral cases. In the current study $48.4 \%$ identified wrong tooth extraction, followed by difficulty in communication, as consequence of not following the correct tooth coding system. Saksena et al reported five complains of wrong tooth extraction within the dental hospital of Manchester, in spite of having a checklist to follow. ${ }^{25}$ Research conducted by Janice et al, and Lee et al also stated that presence of several notation system can lead to dental misconduct. ${ }^{26,27}$ Likewise the disparity in maintaining dental records between different Dental departments within a hospital due to practice of different numbering system will have undesirable consequences as these dental records plays crucial role in serving as medicolegal reports and as forensic evidence. Lastly one of the major prerequisites of clinical audit is maintain uniformity in dental records keeping. Currently there is a lack of studies related to tooth numbering system followed by the different institutes worldwide. In Pakistan as well not much data is available. Hence there's a need for more researches to be conducted in this regards.

\section{CONCLUSION}

This investigation clearly demonstrates that different methods of tooth numbers will be used by the dental professionals. Realistic approach is to make sure that dental professionals have sufficient knowledge regarding the most commonly used numbering systems and are responsive towards the pitfalls in each system. Additionally knowledge of the undergraduates can be improved by adding this component in the curriculum of operative dentistry. Workshops can be organised to improve the level of learning.

\section{RECOMMENDATIONS}

This research identifies the needs for multi-centre research to be conducted that will provide data from the greater sample size.

\section{CONFLICT OF INTEREST}

None declared

\section{REFERENCES}

1. Akram A, Akram A, Hamid AH, Razak J, Hock TT. MICAP-a novel system for identification and communication of dental problems. Int Dent J. 2011;61:31-6.

https://doi.org/10.1111/j.1875-595X.2011.00006.x

2. Scheid RC. Woelfel's dental anatomy. Lippincott Williams \& Wilkins;

2012, 3-41, 8th Edition, ISBN - 978-1-60831-746-2 .

3. Saeed M.H, Khan R, Shah M.U, Akram A and Butt F. Prospects of MICAP Notation in Dental Charting; A Qualitative Study. Acta Sci Dent Sci 1.1 (2017): 30-5

4. Ozdemir MH, Saracoglu A, Ozdemir AU, Ergonen AT. Dental malpractice cases in Turkey during 1991-2000. J Clin Forensic Med 2005;12:137-42.

https://doi.org/10.1016/j.jcfm.2005.01.003

5. Daniele F. The Proper Dental Nomenclature, J Dent Oral Biol. 2018; 3: 1134

6. Akram A, Salam A, Bashir U, Maarof N, Meerah SM. Lesson plan on new method of teeth identification introduced at dental schools in Malaysia and Pakistan, J Dent Education. 2012 1;76:1691-96.

7. Peck S, Peck L. A time for change of tooth numbering systems. J Dent Educ. 1993, 1;57:643-47.

8. Sandham JA. The FDI two-digit system of designating teeth. Int Dent J. 1983; 33: 390-92.

9. Kannan D, Gurunathan D. Comparison of two systems of tooth numbering among undergraduate dental students. Indian J Dent Res. 2016;27:378.

https://doi.org/10.4103/0970-9290.191885

10. Türp JC, Alt KW. Designating teeth: the advantages of the FDI's two-digit system. Quintessence Int. 1995, 1;26,501-04.

11. Keiser-Nielsen S. Federation Dentaire Internationale. Two-Digit System of designating teeth. DP. Dental Pract. 1971;3:6.

12. Yadav SS, Sonkurla S. Sanjeev's supernumerary tooth notation system. A universally compatible add-on to the Two-Digit system. Indian J Dent Res 2013;24:395-96

https://doi.org/10.4103/0970-9290.118009 


\section{Khan U/ Alma BF/ Nayab T/ Inayat A/ Fahim MF/ Khan AW}

13. O'Connor JT. Let's really standardize our tooth numbering system. Oper Dent. 1983;8:73-4.

14. Alt KW, Türp JC. Roll call: thirty-two white horses on a red field. The advantages of the FDI two-digit system of designating teeth. Dent Anthrop 1998, 41-55. Springer, Vienna.

https://doi.org/10.1007/978-3-7091-7496-8_4

15. Akram A, Fuad MD, Bashir U, Pandiyan NJ, Chakravathy K, Vishnumukkala TR, Madlena M. An assessment of clinical application of a new tooth notation for primary teeth. J Int Dent Medi Res. 2015;8:7.

16. Blinkhorn AS, Choi CL, Paget HE. An investigation into the use of the FDI tooth notation system by dental schools in the UK. Europ J Dent Educ. 1998 Feb;2:39-41.

https://doi.org/10.1111/j.1600-0579.1998.tb00034.x

17. Al-Johany SS. Tooth Numbering System in Saudi Arabia: Survey. Saudi Den J. 2016; 1;28:183-88

https://doi.org/10.1016/j.sdentj.2016.08.004

18. Sharma PS, Wadhwa P. Evaluation of the FDI two-digit system of designating teeth. Quintessence Int, Dent Dig. 1977;8:99.

19. Elderton RJ. Keeping up-to-date with tooth notation. Brit Dent J. 1989; $166: 55$

https://doi.org/10.1038/sj.bdj.4806709

20. Ahlberg, J.E., 1987. We must get the numbers right. Fe'de'ration Dentaire Internationale News. 158, 8-9.
Knowledge of Dental Notation System in a Dental Teaching Hospital of Karachi

21. Manica S. A new website to aid the interpretation of ante-mortem dental records: www. internationaldentalcharts. org. J Forens Odontstomatolog. $2014 ; 32: 1$.

22. Toureno L, , Park JH, Cederberg RA, Hwang EH, Shin JW. Identification of supernumerary teeth in $2 \mathrm{D}$ and $3 \mathrm{D}$ : review of literature and a proposal. J Dent Educ. 2013, 1;77:43-50.

23. Tooth IQ: supernumerary tooth. 2011

Cited from:- www.webcitation.org/5uW55SxoA. Accessed: August 14, 2011. Google Scholar

24. Pogrel MA. Tooth notation. Brit Dent J. 2003,11;195:360. https://doi.org/10.1038/sj.bdj.4810581

25. Saksena A, Pemberton MN, Shaw A, Dickson S, Ashley MP. Preventing wrong tooth extraction: experience in development and implementation of an outpatient safety checklist. Brit Dent J.2014;217:357.

https://doi.org/10.1038/sj.bdj.2014.860

26. Lee JS, Curley AW, Smith RA. Prevention of wrong-site tooth extraction: clinical guidelines. J O Maxillofac Surg. 2007, 1;65:179399.

https://doi.org/10.1016/j.joms.2007.04.012

27. Janice S L, Arthur W C, Richard A S. Prevention of wrong site tooth extraction: Clinical guidelines. J Oral Maxil Surg 2007;65:179399.

https://doi.org/10.1016/j.joms.2007.04.012 